The bridge, which took a little more than eight

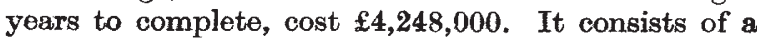
main span of $1,650 \mathrm{ft}$. with a clearance of $170 \mathrm{ft}$. over the central $300 \mathrm{ft}$. of span, and ten approach spans. It accommodates a roadway $57 \mathrm{ft}$. wide, four railway tracks and two footways. The principal parts of the main-span truss are of silicon steel with a modulus of elasticity of $30,500,000 \mathrm{lb}$. per sq. in. Analytical methods of calculation were used, arithmetical processes being carried out by calculating machines. Calculations were required for the following combinations of loads : dead load, live load and impact, horizontal force, centrifugal force, wind loads and temperature variation. Of the total weight of the main truss material, the proportions attributable to various loads are as follows: dead weight of arch, 35 per cent ; dead weight of deck, 23 per cent ; live load and impact, 26 per cent; wind, 8 per cent; horizontal force, 2 per cent; and temperature, 6 per cent. Tests on model members were made by means of a testing machine of 1,250 tons capacity, capable of dealing with tension and compression specimens up to $50 \mathrm{ft}$. long and bend test specimens $20 \mathrm{ft}$. long. Tests of the arch after completion indicated a span $\frac{3}{4}$ in. in excess of $1,650 \mathrm{ft}$., a difference partly due to unavoidable errors of survey and possibly partly caused by shrinkage of the concrete below the bearings. The bridge was erected by Messrs. Dorman, Long and Co., of Middlesborough.

\section{The Indian Antiquary}

WiтH the December issue, which, through labour troubles, has only just become available in Great Britain, the Indian Antiquary ceases publication. The demise of this valuable periodical will be greatly regretted by all who are interested in Indian studies. For more than sixty years it has served as a medium of publication for original communications of the highest standard of scholarship, dealing with the ethnology, archæology, history, linguistics, folk-lore and religions of India. The Indian Antiquary was founded by the late Dr. J. Burgess in 1872 and later was acquired by the late Sir Richard Temple as his sole property. Under his editorship-he was editor-in-chief for forty-six out of the fifty-one years of his connexion with it-the services of the Indian Antiquary to the cultural history of India were incalculable. Sir Richard Temple's wide knowledge of orjental subjects made him an ideal editor of a journal of this type, not merely because of his own numerous contributions to its pages, but also for the stimulus and assistance he was able to give to the studies of others. As one result of his influence may be mentioned Epigraphia Indica, the official record of epigraphic work in India, which was a direct out. growth of work initiated by the Indian Antiquary. In $1924 \mathrm{Sir}$ Richard Temple transferred his interest in the journal to a small private company, and the Royal Anthropological Institute assumed responsibility for its publication. Sir Richard Temple retained the editorship, at first in association with Mr. S. M. Edwardes, and after his death in 1927 with Mr. C. E. A. W. Oldham, who became editor-in-chief on Sir Richard's death in 1931. Owing to financial conditions the Royal Anthropological Institute felt compelled to sever its connexion with the Indian Antiquary in 1932 and during the past year it has been carried on by the editor in order to complete publication of matter in hand.

\section{Protection of Power-Transmission Plant from Lightning}

A series of articles on lightning by J. F. Shipley which is being reprinted in Distribution of Electricity, a paper published by W. T. Henley's Telegraph Works Co., gives a résumé of what has been accomplished in recent years in protecting transmission lines and engineering plant connected with them from damage from lightning. The effect of a lightning flash on a transmission line is to puncture the insulators or make them flash over, sometimes causing a short circuit which shuts down the supply. During the last forty years a very large number of devices have been employed to protect the lines, such as air-gaps, water-jets, oxide films, etc. These have been found only partially effective. The ideal arrester would be some link between the line and earth which would have infinite resistance at the normal pressure, but when for any reason that pressure increased by 10 or 20 per cent, the resistance should become practically zero, thus furnishing the impulsive rush of electricity with a safe path to earth. A recent device consists of a solid block of a material consisting of conducting particles of metallic oxide diffused in a baked clay which is microscopically porous. It is similar to porcelain in texture and mechanical strength and normally has almost infinite resistance. As soon as the electrical pressure across a block of it rises above a definite value its resistance decreases at a very rapid rate. If we double the voltage, the current it will pass increases more than twelve times. The material seems to have two names, 'thyrite' and 'ocelit'. As it is an artificial product and can be accurately controlled, it looks as if a real step forward has been made in the design of these arresters, or 'safety-valves' as they are often called.

\section{Electric Waxing of Floors}

Helios, a German electrical trade journal printed in Leipzig, gives descriptions in three parallel columns in German, French and English respectively of the latest electrical devices. In the issue for November 19 an interesting description is given of tests on an electric floor-waxing device, with and without a suction apparatus for the simultaneous collection of dust. The tests were carried out in the laboratories of several universities as well as in commercial test rooms. When the suction device was used there was no appreciable change in the percentage of dust in the air caused by the whirling of the waxing apparatus. When no suction device was employed the percentage of dust in the air increased as much as seven to eight times the normal quantity. In this case the dust on the floor was whirled upwards by the waxing machine. With the suction device it is not necessary to clean the room so often and there is no need to have a special vacuum cleaner. The dust which settles on furniture prolongs the work of cleaning, and certain works of art are damaged, while it is 
also a menace to health. In many workshops the dust impairs the quality of the finished goods. The floor-waxing machine with suction device should prove specially useful in hotels, hospitals and sanatoriums.

\section{Industrial Physics}

The address which Dr. Paul D. Foote delivered before the American Physical Society as retiring president appears in full in the February issue of the Review of Scientific Instruments. In it he points out how inadequately industrial physics has been represented on the Council of the Society, and how as a consequence much of the work of the members of the Society has failed to attract the attention of industrial executives and they are unable to see that there are places for physicists in their organisations. It has been left to large corporations like the General Electric Company to show how much physicists can do for industry. Dr. Foote considers that the training in physics in most of the American universities fits a man neither for industry nor for a position in a junior college, and that industry has to look to the engineering rather than to the physics departments for men adequately trained in the fundamentals of classical physics in preference to those superficially acquainted with the latest developments of quantum mechanics. He hopes that the newly-formed American Institute of Physies and the new journal Physics will secure more intimate contact between physics and industry, and that the attitude of the Society towards applied physics in the next few years will insure that physics becomes a real profession rather than an academic avocation. Since the foundation of the Institute of Physics, in London in 1918, the position of British physicists has improved. Lord Rutherford recently pointed out thàt there has been a rapidly growing recognition of the importance of the physicist, not only in the academic world but also in industry, and he considers that the Institute of Physics can justly claim some of the credit for this.

\section{Tests for Accident Proneness}

UNDER the title "Tests for Accident Proneness", the Industrial Health Research Board has published the results of a further investigation into the factors involved in "accident proneness" which have engaged its attention for several years (Medical Research Council : Industrial Health Research Board. Report No. 68 : Tests for Accident Proneness. Pp. iv +37. London: H.M. Stationery Office, 1933. 9d. net). Previous work had established that certain individuals are inherently more liable to sustain industrial accidents than others exposed to the same risk. By the investigations of E. Farmer, E. G. Chambers and F. J. Kirk now reported, it has been established from experiments with groups of dockyard apprentices and naval artificers that, within the groups studied, poor resthetokinetic co-ordination (defined as the ability to do certain sensori-motor tests) is associated with a liability to sustain an undue number of accidents. The results do not suggest that resthetokinetic coordination is associated with accident proneness in all occupations, although it is probably associated with it in groups doing similar work to those tested. Deficiency in this function, however, only accounted for a part of the accidents sustained, and it is evident that only one of the factors involved in accident proneness has thus far been isolated and evaluated. Even this, however, makes a definite step towards the practical goal of detecting beforehand those specially liable to accident and warning them against entering dangerous occupations. No significant relation was observed between intelligence and accidents in any of the groups, and in two of them accident proneness did not decrease with age and experience. It does not follow, however, that in groups employed on different work, variations in intelligence may not play a part in accident proneness.

\section{Scientific Survey of South-Eastern Polynesia}

The Bernice P. Bishop Museum, Honolulu, has organised an expedition, to be known as the Mangareva Expedition, for the study of the little-known parts of south-eastern Polynesia. Because other means of transportation are unavailable, the Expedition is provided with two ships. The Islander (Capt. W. G. Anderson), a high-powered sampan, was to leave Honolulu on March 1 and during a six months' cruise will serve as a 'master ship' for scientific workers who will conduct investigations chiefly at Mangareva, Oeno, Pitcairn, Rapa, Tubuai, Rurutu, Raivavae, and Rimitara islands. The second ship, the cutter yacht Tiare Tahiti (Capt. Robert S. Burrell), under charter from May until October, will serve primarily as a 'transfer ship' for the ethnologists at work in Mangareva and among the three hundred and sixty islands of the Tuamotu Archipelago. The chief purpose of the Expedition is to record the data regarding native races, flora and land fauna, which are disappearing at a surprisingly rapid rate. Incidental observations on geology, marine zoology and general oceanography will also be made. The scientific staff includes Dr. Peter $\mathbf{H}$. Buck, Kenneth P. Emory and J. Frank Stimson, ethnologists ; Prof. Harold St. John and Raymond Fosberg, botanists; Dr. C. Montague Cooke, Jr., and Donald Anderson, malacologists; and E. C. Zimmerman, field entomologist. Dr. C. Montague Cooke, Jr., has been appointed leader of the Expedition.

\section{A History of Vegetables}

The Gardeners' Chronicle of March 3 publishes a report of a lecture on "The Introduction of Vegetables" by Mr. E. A. Bunyard. It comes as somewhat of a surprise to find that many of our common vegetables were once regarded as harmful plants, or were the subjects of religious prohibition. The broad bean, for example, was forbidden to the Egyptian priests, though later it was the cause of 'bean-feasts' to a bean god. Garlic, cabbage, asparagus and spinach have all had a somewhat chequered history. The scarlet runner bean was long prevented from becoming a table delicacy by its value for ornamental purposes. Tomatoes were first suspected of being poisonous, then became medicinal, and it was not until the 'eighties of last century that their nutritive 